\title{
Education in Adult Advanced Cardiac Life Support Training Programs: Changing the Paradigm
}

From the Department of Internal Medicine, University of Michigan Medical School, Ann Arbor* and the University of Massachusetts Medical School, Worcester (retired). ${ }^{\dagger}$

*James M Atkins, MD; Allen Braslow, PhD; William Kaye, MD; Karen J Kelly, RN, MSEd; Katherine A Littrell, RN, MEd; Mary Beth Mancini, RN, MSN; Lynn Mandel, $P h D$; and Lawrence D Newell, $P h D$.
To develop a consensus for change in the educational aspects John E Billi, MD* George E Membrino, PhD ${ }^{\dagger}$ Members of the Advanced Cardiac Life Support Education Panel${ }^{\ddagger}$ the American Heart Association appointed panel members to of the Advanced Cardiac Life Support (ACLS) Training Program, engage in a consensus process. At a preconference meeting held in the fall of 1991, panel members received broad input from experts in adult education, experienced ACLS educators, and resuscitation scientists. The panel then developed a statement based on the preconference discussions and presented it at the National Conference on CPR and Emergency Cardiac Care held in February 1992. The conference's recommendations and the process that led to them are described in this paper.

The key conclusions of the consensus process are as follows. The purpose of ACLS programs is the education of health professionals whose jobs include the management of patients in arrest or near-arrest. The goal of each ACLS course is to have each participant succeed in acquiring the skills and knowledge required for resuscitation. Aspects of the course which threaten failure or raise anxiety should be minimized or eliminated. ACLS course directors are strongly encouraged to design courses whose content and presentation are best suited to the training, experience, and needs of the course participants. Flexibility is strongly encouraged. Evaluation (testing) should be used primarily for its educational value, to help both learners and instructors identify areas needing improvement. The problem learner should be identified as early as possible and should receive intensive remediation to achieve the goal of every participant acquiring the targeted skills and knowledge. Because skill retention is variable, rescuers should practice skills frequently in regular refresher sessions. At a minimum, retraining every two years is strongly recommended.

[Billi. JE, Membrino GE: Education in adult advanced cardiac life support training programs: Changing the paradigm. Ann Emerg Med February 1993;22 (pt 2):475-483.] 
OVERVIEW OF ISSUES

Work on changing the paradigm for Advanced Cardiac Life Support (ACLS) education started at the conclusion of the 1985 National Conference on CPR and Emergency Cardiac Care (ECC). The literature was reviewed and issues were identified during the summer of 1991 in preparation for the preconference meeting held in September 1991. The conclusions of this meeting were used as the basis for the ACLS Education Panel presentations at the National Conference on CPR and ECC held in February 1992.

The statement from the preconference meeting included a number of issues that required examination. The educational philosophy, educational design, program flexibility, and methods of evaluation of the ACLS Training Program were defined as key issues. The panel members developed a 90-minute interactive program for the national conference to address these issues. A major objective of the panel planning was to elicit as much input from the conference participants as possible. The conference participant interest level and the controversies explored during the session led to an expansion of the panel's discussion time to longer than two hours.

A 20-item questionnaire was distributed to all in attendance. Of a total of 150 conference participants in the panel discussion, 130 (87\%) returned questionnaires. This report consists of three parts: the preconference statement, the conference panel presentations, and the conference participant input. Implementation of these recommendations is now the task of the ECC and its ACLS Subcommittee.

Brief Review of the Role of Education in Assisting the ACLS Training Program in Achieving its Present Success The sole purpose of the ACLS Training Program is the education of health professionals whose jobs include the management of arrest and near-arrest patients. Recognizing this, the 1979 national conference and subsequent JAMA

Supplement ${ }^{1}$ stated that the term certified is equivalent to successful completion of the educational program, indicating "satisfactory completion according to cognitive and performance testing at the time of testing." There was no intent to guarantee or warrant future performance or to indicate or suggest a form of licensing. At present, the term certified is no longer used. Participants receive a card that indicates successful completion of the course.

The 1985 national conference had as one of its six conference objectives "to make recommendations regarding education and evaluation methodologies, including the effectiveness of teaching and the target population for the CPR/ECC Programs."2 Despite this objective, only limited coverage of educational issues appeared in the 1985 conference output. ${ }^{3}$

Over the past 18 years, the ACLS model of resuscitation education has been copied and modified by many subsequent programs, including the American College of Surgeons' Advanced Trauma Life Support (ATLS) Program and the American Heart Association's (AHA's) Pediatric Advanced Life Support (PALS) Program. The principles of adult learning incorporated into the ACLS program are as valid today as they were in 1974. At its best, ACLS is a program that emphasizes learning successes and minimizes the negatives; allows each participant to learn at his/her own pace; emphasizes hands-on practice and interactive learning; and asks instructors to establish connections between new learning and pertinent knowledge, skills, and other experiences. The program avoids making matters appear so complex that the participant is overwhelmed and unnecessarily discouraged.

The ACLS Training Program is unlike most continuing education courses in which the participant is often lulled into becoming a passive learner. The ACLS program provides a body of knowledge through a comprehensive textbook that is updated periodically and supplemented when needed. The program provides an educational design that is flexible and adaptable to varying needs and skills of individuals, professions, and facilities. Moreover, the program provides the format for the teaching and practice of skills in a positive learning environment. In the practice sessions, the ACLS program provides the opportunity for interaction among all members of a code team in a setting that promotes learning and reduces stress. Unlike most continuing education programs, ACLS provides each individual the opportunity to evaluate his/her own knowledge, skill, and attitude. In its best form, the ACLS program emphasizes learning and success rather than stress and failure.

Today, the goals remain the same. Those who developed the program in 1974 probably had little idea that the ACLS textbook would today become one of the bestselling medical texts in the world. The ACLS experience has proved that committees composed entirely of volunteers working within a not-for-profit association can and have accomplished what the private and public sectors have been unable to accomplish in so many areas of medicine - effective professional education.

Review of the Preconference Fact- Finding Meeting To comply with the consensus process used in the National Conference on CPR and ECC, the ACLS Education Panel built upon the work of a preconference meeting held in Dallas, Texas in the fall of 1991. At that meeting, broad 
input was obtained from experts in adult education and participants experienced in the implementation of the ACLS Training Program. The key issues and recommendations identified through this process served as the basis for the presentations made by the ACLS Education Panel at the national conference. The full scope of the recommendations (with rationales) is presented in the next section of this paper.

The most controversial of the preconference recommendations surrounded the changes in the educational paradigm. These recommendations included the elimination of "pass" and "fail" from the ACIS Education Programs, the awarding of course completion documentation to all active participants regardless of performance on examinations, and an intensive focus on early identification and remediation of participants with problems.

The National Conference: ACLS Education Panel Presentations and Conference Participants' Feedback A Synopsis of Panel Presentations and Feedback Presentations from the panel members are summarized below. Following each major issue, we have included a summary of participant feedback on that point. In general, participants agreed with almost all of the points made by the panel. This included the almost universal agreement with the philosophy that the primary goal of the ACLS Training Program was the education of health professionals in the skills and knowledge required for resuscitation and not the certification of clinical competency. The participants also supported increased flexibility in ACLS course structure and presentation and proposed revisions in both the ACLS textbook and the role of evaluation in the training program. Major controversy arose over one point: the criteria for awarding course completion documentation. This is discussed more fully below.

Detailed Panel Presentations and Conference

\section{Participants' Feedback}

\section{The Educational Philosophy of ACLS}

The sole purpose of the ACLS program is education. The course is designed to assist in the education of health professionals whose jobs include the management of patients in arrest or near-arrest. Toward this end, the AHA, in conjunction with other interested national and international organizations, has assumed the responsibility of reviewing the scientific data and developing guidelines for resuscitation. The AHA has used these guidelines to develop educational programs, materials, and a training network, all of which can be used to assist in the training of the resuscitation community. Sixty-four percent of the participants supported this recommendation.

2. The ACLS Goal: The Education of Each Participant

It should be the goal of each ACLS course that every participant succeed in acquiring the skill and knowledge required for resuscitation. The course must be designed to encourage the learning process. It must minimize performance anxiety, fear of "failing," and complexity. Therefore, all components which might be viewed as threatening "failure" should be modified to provide a positive learning environment that fosters the acquisition of skills and knowledge. Rather than focusing on whether all participants have reached some predetermined competency level, the course faculty should focus on improving each individual participant's ability regardless of his/her precourse level. It may be more valuable to improve the ability of one novice than to verify the performance of ten accomplished participants. Eighty-eight percent of the participants supported this recommendation.

\section{The ACLS Textbook}

The ACLS textbook ${ }^{4}$ material expands upon the Guidelines and Recommendations of the AHA to explain in depth the scientific basis of resuscitation practices. The textbook currently, however, includes information far in excess of that needed to perform satisfactorily in a resuscitation attempt. The core material is buried in the ACLS textbook, which may intimidate participants whose primary interest is in acquiring resuscitation skills and simple treatment skills. Because of this, the ACLS textbook is being reorganized to include an initial chapter, "Essentials of ACLS," which includes only the specific skills and knowledge required for a resuscitation attempt. This chapter can be used in conjunction with the rest of the ACLS text, which provides the rationale and evidence for the practices. Course directors may design the course to use only the material in the "Essentials of ACLS" chapter. Course directors are encouraged to determine which additional text sections should be included as part of the course, based on the needs of the participants. Course directors then must communicate that assignment to the participants, in advance of the course. The course director must strongly encourage all participants to read relevant parts of the ACLS text, using it as a reference to increase the depth of understanding of the science underlying resuscitation practices, as appropriate for that rescuer's abilities and needs.

The participants' feedback included a strong plea for a "basic core text." The participants supported either separating core material out of the text as a separate shorter booklet or highlighting the core material in an early chapter. This would allow instructors to direct the participants to the material that requires mastery to maximize the value of the course. The addition of a chapter that included the emotional issues of resuscitation was suggested for the future. 
4. Course Content, Design, and Flexibility

Course directors are strongly encouraged to tailor the content, structure, and schedule of courses to meet the educational needs of that group. Examples of course variations will be included in the instructors' manual, including a suggested one-day provider course modeled after the retraining course. ${ }^{5}$ Specifically, flexibility in course design is encouraged. This may include designs which use only one segment of the ACLS course to meet specific educational needs ${ }^{6}$ (eg, adding the electrical therapy section to a BLS course). On the other extreme, a director could design a full ACLS course over a prolonged period, including a full spectrum of resuscitation skills and knowledge.

While flexible course design is encouraged, the value of the interdisciplinary approach should be preserved. Participants with differing resuscitation roles (physicians, nurses, paramedics) should be scheduled to practice skills together, if possible.

One strategy that course directors may choose is to decrease dramatically the time spent in lecture. Course directors are responsible for determining the selection and length of didactic lecture presentation, including the determination of which aspects of a topic will be covered and which will be deleted. When lectures are used, the lecturer need not include all slides from the ACLS slide set. The lecturer should select slides from the ACLS slide set and from personal collections that best achieve the objectives of the lecture and the courses. Participant needs should dictate the optimal content and presentation mode for each component of the course.

A course may be designed with few or no lectures, provided that all materials needed to meet the education objectives can be presented in a satisfactory manner, such as through interactive sessions and skill stations. Videotapes or other innovative teaching materials may be substituted for lectures, provided they assist the course faculty and participants in achieving the educational objectives.

The conference participants supported the concept of a higher degree of flexibility in course design and presentation, based on the needs of individual participants in the roles they will play in a cardiac arrest. Strong encouragement was made for flexibility in course format, including the one-day program and the modular course over the period of weeks. Support was also given for special programs utilizing supplemental material from the text for appropriate groups of participants. Likewise, there was support for the concept of incorporating portions of the ACLS material into other training programs, either outside of a formal AHA training course or within it. Examples include the use of the arrhythmia diagnosis and treatment section in a critical care unit nursing inservice and the use of the intubation training station in a BLS course for certain emergency medical personnel.

5. Evaluation: The End of "Passing" and "Failing"

The role of participant evaluation (formerly "testing") must be consistent with the purpose of the course: education. Evaluation serves multiple purposes:

a. To inform individual participants of specific problem areas for further work.

b. To guide instructors on areas in which specific participants need help.

c. To provide the course director and instructors with an assessment of the educational success of the course.

If the course director and instructors have properly designed and conducted the course, the participants should demonstrate a high degree of acquisition of the specific knowledge and skills that were the educational objectives of that particular course. If the evaluations indicate a high percentage of participants performing poorly, this represents a problem to be solved by the course director and instructors. Participant shortcomings should be reviewed by the course director and faculty, and additional help should be given to those who need it. The goal is the education of all participants.

One way to view the evaluation process is as a triage system that assists the faculty in early identification of those participants who need additional help. This triage function permits participants to learn at their own rate. Individual participant differences are acknowledged, so that those who are doing well can move quickly through evaluation, while those who need additional time will not feel threatened. The philosophy must be to teach until the participant achieves the level of success he or she seeks, even if it takes added effort by both the learner and the instructor. While it is recognized that ACLS courses vary greatly in their personnel and resources, every effort should be made to remediate participants with poor performance evaluation. Some ACLS courses have reported success with the use of a remediation station that operates concurrently with other evaluations stations; all problem participants are referred to the remediation station for further help. Other courses stress an "open practice" session after the scheduled teaching stations, staffed by an expert instructor. Participants having difficulty can be referred to that session; other interested participants also may attend to improve skills further. Another model utilizes the written examination as an educational instrument. After the 
examination is completed, all participants review the rationale behind questions missed with an expert instructor in an interactive small-group session. Participants can use remediation time to learn without threat of failure.

During evaluation, the value of the participant's waiting times should be respected. Constructive use of this time for educational value could include discussion of written examination problems, station practice, case presentation, or discussion of unknowns. The cost of the instructor time required must be compared with the negative impact on participants of using their time unproductively.

In the interest of conserving instructor time for those who most need it, participants who are already proficient can be passed through the evaluation phase quickly and efficiently. To that end, the instructor may indicate proficiency at the time the skill is taught, eliminating the need for further evaluation of that participant in that skill. The time freed will allow that participant to focus on areas of greater personal need. Early personal feedback to participants on areas of proficiency and areas needing improvement should be provided for all skill and knowledge evaluations.

Conference participants supported the use of evaluation to identify and remediate problem participants and to provide an assessment of the educational success of the course.

6. Course Completion and Its Implications

In the field of ACLS, the AHA is responsible for the translation of the scientific data on resuscitation into educational materials and the support of an educational network to foster the use of these educational materials in training health professionals involved in resuscitation. The hospitals, county health departments, emergency medical systems, and other employing and regulatory entities are responsible for the certification of clinical competency of health professionals. In the discharge of that responsibility, those entities may choose to adopt the criteria and evaluacion instruments developed for the ACLS education program. In this light, a hospital could assess its providers' clinical competency using ACLS criteria. This assessment might occur by itself or in the setting of a fullscale ACLS course conducted at that institution.

Consistent with the philosophy of ACLS as education, the AHA has removed the term certified from its cards and course materials in the past five years. To further emphasize this philosophy, the panel recommended that the ACLS program should provide course participants with a document of course participation (eg, a card) when the following conditions are met. First, the course is designed to teach (at a minimum) the material covered in the "Essentials of ACLS" chapter. Second, the course includes evaluation of the participant in both the knowledge and skills covered in that chapter. Third, the learner has participated in the course, including teaching and evaluation activities mentioned above.

As previously mentioned, any participant identified as having difficulty must receive focused attention to improve his/her knowledge and skills. If, despite this focus on teaching and remediation, a participant is still having difficulty, he/she should be given specific feedback on the areas needing further remediation and suggestions on how to improve the skills. The panel recommended that this participant should be given the same course completion card to document participation in the training program.

Courses or educational programs which use parts of the ACLS course but do not contain the minimum content of the "Essentials of ACLS" chapter may, of course, still be part of a very valid educational program. Such programs will not issue ACLS course completion cards. These programs likely will qualify for and may be able to award health professional continuing education credit. The AHA encourages broad and flexible use of its materials in educational programs and specifically encourages use of the components of ACLS participant evaluation appropriate to the particular program.

During the discussion, the majority of panel members expressed agreement that the ACLS Training Program needed to revise the concept of the awarding of a "card" and the value of "pass" and "fail." Both of these aspects were viewed as exerting a negative educational impact. In keeping with the statement of the preconference meeting, most of the panel recommended their elimination. One member of the panel expressed concern that smaller facilities would not have the ability to evaluate the clinical competency of their own personnel in the performance of resuscitation skills. In contrast to the panel, many of the audience participants raised strong objection to the recommendation. Most of the participants strongly preferred to retain both a "card" and the "pass/fail" criteria in the program. Many participants disagreed with the position presented by the panel that the elimination of these vestiges of certification would enhance the educational value of the program by removing the negative aspects of testing and failing.

7. Emotional Issues in ACLS Education and Performance

Course directors should attempt, in an interactive (discussion) setting, to deal with the emotional aspects of 
resuscitation attempts, including guilt following a failed attempt. This recommendation was not discussed during the panel discussion.

Response to the 20-Item Questionnaire In addition to the panel presentations and conference participant feedback described above, the panel also solicited input from the conference participants through the administration of a participant feedback questionnaire. The panel members agreed in advance upon the 20 position statements in 5 categories: educational philosophy, course content and flexibility, the ACLS textbook, role of evaluation, and the implications of course attendance. Each position statement was worded in such a way as to provide a positive statement of the consensus opinion of the panel. The wording was definitive, where possible, to elicit a definitive response from the respondent. Each position statement was followed by a five-point Likert-type scale with the following anchors: strongly agree, agree, neutral, disagree, and strongly disagree. There was also room for written comments on each position statement. The responses were anonymous.

A total of 130 questionnaires were received $-87 \%$ of the number of participants who attended the panel discussion. The Appendix contains the full text of each of the position statements included in the participant feedback questionnaire. Following each position statement is the result of the questionnaire, collapsed into the percent that strongly agree or agree compared with the percent that disagree or strongly disagree with the position statement.

On most of the questions, the respondents agreed with the position statement as worded. Most of the negative comments related to the controversy discussed above: the criteria for awarding course completion documentation. In all, $57 \%$ disagreed or strongly disagreed with the position statement that the terms pass, fail, satisfactory, and unsatisfactory should be eliminated from evaluation forms (position statement 12). Likewise, 61\% disagreed with the position statement that the documentation of course participation should be given to participants even if evaluation stations show they need improvement in one or more areas of skill or knowledge (position statement 15). On the final position statement, regarding whether course directors should release detailed written evaluation results to participants to provide documentation of individual skill levels, the responses were split. Major concerns were voiced regarding the logistical problems and legal implications of such a step.

Final Consensus Recommendations Following the panel presentations, conference participant feedback, and review of participant feedback questionnaires, the panel formulated consensus recommendations. The final consensus represented a moderation of the original recommendations of the panel based on the depth and intensity of the feedback received from conference participants.

1. The goal of the ACLS Training Program is to assist in the education of health care professionals whose jobs include the management of the arrest or near-arrest patient. The goal of each ACIS course should be the success of each participant in acquiring the skills and knowledge required for his/her role in resuscitation.

2. The course should be designed to encourage the learning process. It should minimize performance anxiety, fear of failing, and complexity. Components which might be viewed as threatening "failure" should be modified to provide a positive learning environment that fosters the acquisition of skills and knowledge.

3. The role of evaluation in the ACLS course is to determine what the participant has learned, to inform individual participants of specific problem areas for further work, to guide instructors in the areas in which specific participants need help, and to provide the course directors and instructors with an assessment of the educational success of the course.

4. If the course has been designed to meet the needs of the participants and is successfully carried out, the participants should show a high degree of acquisition of the targeted knowledge and skills. If evaluation of the learners shows that a high percentage are performing poorly, this represents a problem to be solved by the course directors or instructors.

5.As soon as possible during the course, the faculty should identify those participants who are having difficulty with the acquisition of skills and knowledge set as the targets for the course. Course directors and instructors should identify the source of the problem (inadequate preparation, unrealistic expectation, problems with teaching a particular skill, etc.). Efforts to remediate the participant should begin early and should continue throughout the course and after the course, if required. It was the consensus of the panel that course participants who fail to acquire targeted skills and knowledge by the end of the course must be allowed the opportunity for unlimited remediation at subsequent courses, without additional charge. This practice is consistent with the philosophy that the goal of the course is the acquisition of skills and knowledge necessary for each individual's role in resuscitation. 
6. The panel strongly endorsed flexibility in course design. Course directors should assess the needs of the group of participants and then design the content, structure, method of presentation (lecture, teaching stations, interactive group discussion, etc.) and the duration of the ACLS course to meet those needs. A properly designed one-day course is appropriate for some participant populations.

7. In order to be considered an AHA ACLS provider course and to issue documentation of course completion, the course must include teaching and evaluation of the core knowledge and skills:

Teaching

Myocardial infarction

Cardiovascular pharmacology

Arrhythmia recognition and therapy (including the ACLS algorithms)

Special resuscitation situations

Airway adjuncts

Endotracheal intubation

Intravenous techniques

Electrical therapy

Megacode team practice

Evaluation

Basic Life Support

Airway adjuncts and intubation

Arrhythmia recognition and therapy

Megacode

Written examination

8. Training programs that use part of the ACLS course but do not contain the minimum ACLS course content may, of course, be part of a very valid educational program. Such programs will not issue AHA ACLS course completion cards. These programs likely would qualify for health professional continuing education credit and may be able to award such credits through the usual national approval process. The AHA encourages broad and flexible use of its materials, including components of the ACLS course.

9. The value of interdisciplinary training should be preserved so that health professionals with different roles in resuscitation can practice together to learn to function as a team.

10. The ACLS textbook should have a clear demarcation of the core material. The textbook will have a new initial chapter entitled "Essentials of ACLS," which includes all core facts and expands upon the current Chapter 16, "Putting It All Together." This will help the learner focus efforts on the most important material in preparing for the course.
11. The section of the textbook and course covering the resuscitation of infants and children will be removed from the core material. The panel supported the consensus of conference participants that some pediatric material be retained within the ACLS textbook, either as a separate chapter or as a reduced version of the PALS textbook. The panel also agreed that the inclusion of pediatric resuscitation content in an ACLS course was at the course director's discretion. but that the awarding of PALS course completion cards can occur only if the course satisfies all PALS course criteria and approval processes.

12. The ACLS course should provide participants with documentation of course completion when the following conditions are met: a) the ACLS course is designed to teach at least the minimum knowledge and skills defined above (the core material), b) the course includes evaluation of the participant in both the knowledge and skills covered in the core material, c) the individual has participated in the course (including teaching and evaluation activities), and d) the participant has remediated deficiencies adequately.

13. In the event that a participant with problems cannot be remediated successfully by the instructors during a course, it is recommended that this participant be allowed to continue remediation efforts at a subsequent date without additional charge. Once remediation is completed, the participant would receive a course completion document. Regardless of the final. performance, the participant may receive continuing education credit.

14. To retain proficiency in ACLS skills and knowledge, rescuers need regular refresher sessions, including a review of both resuscitation decision making and psychomotor skills. ${ }^{7}$ Therefore, ACLS providers should retrain as often as needed, based on their role in resuscitation and the frequency of use of skills at work. Frequent refresher sessions are encouraged. At a minimum, retraining every two years is strongly recommended.

COMMENTARY

The ACLS training program has been very successful in teaching skills and knowledge required by a rescuer in a resuscitation attempt. To prepare the participant for the actual performance of resuscitation, the course requires expanded coverage of the humanistic aspects of resuscitation, including the emotional response of the rescuer, guilt 
at a failed attempt, dealing with survivors and family members, life support and resuscitation decisions, and other psychological, ethical, and legal issues. Course directors should attempt, in an interactive (discussion) setting, to deal with these humanistic aspects of actual resuscitation practice. This will be complemented by a new chapter in the ACLS textbook on psychological and ethical aspects of resuscitation.

This conference began the national dialogue regarding the criteria for the issuance of course completion documentation and its impact on achievement of the educational goals of the ACLS and all formal resuscitation training programs. This discussion must continue to explore fully the implications of change. Further study is required to help these suppliers and consumers of ACLS course completion documentation understand the full implications, positive and negative, of any future decisions to change criteria for course completion. The large degree of dependency that has evolved among systems that train rescuers in ACLS and those that demand documentation of clinical competency needs further exploration in an effort to assess whether the reliance upon course completion documentation is productive or counterproductive to the educational objectives of the program. We may be able to gather insights from research in adult professional education to help inform this debate and arrive at the most constructive conclusion.

\section{RESEARCH INITIATIVES}

The panel recognized that further research is needed to develop the optimal evaluation system for the ACLS education program. This should include evaluation of the participants, the instructors, and the overall program. The goal should be to assess the degree to which the ACLS program is meeting its objective: to educate rescuers. Further investigation is also needed to determine the impact that testing to "pass" and "fail" has on the educational success of the program. Because retention of skills and knowledge is variable, the program would benefit from further studies of innovative refresher programs and other retention strategies.

\section{REFERENCES}

1. Standards and Guidelines for Cardiopulmonary Resuscitation (CPR) and Emergency Cardiac Care (ECC). JAMA 1980;244:453-509.

2. Proceedings of the 1985 National Conference on Standards and Guidelines for Cardiopulmonary Resuscitation and Emergency Cardiac Care. Circulation 1986;74 (6, pt 2):IV 1. 153.

3. Atkins, JM: Education and evaluation in emergency cardiac care programs.(CPR and advanced cardiac life support): State of the art. Circulation 1986;74 (supp! IV):IV18-22.
4. Textbook of Advanced Cardiac Life Support, ed 2. Dallas, Texas, American Heart Association, 1990

5. Kaye W, Wynne G, Marteau T, et al: An advanced resuscitation training course for preregistration house officers. J Royal Coll Physicians Lond 1990:24:51-54.

6. Kaye W, Mancini MF, Rallis S, et al: Education aspects: Resuscitation training and evaluation, in Kaye W, Bircher NG, (eds): Cardiopulmonary Resuscitation. New York, Churchill Livingstone, Inc, 1989

7. Stross JK: Maintaining competency in advanced cardiac life support skills. JAMA 1983;249:3339-3341

\section{Appendix.}

Participant Feedback Questionnaire* and Results

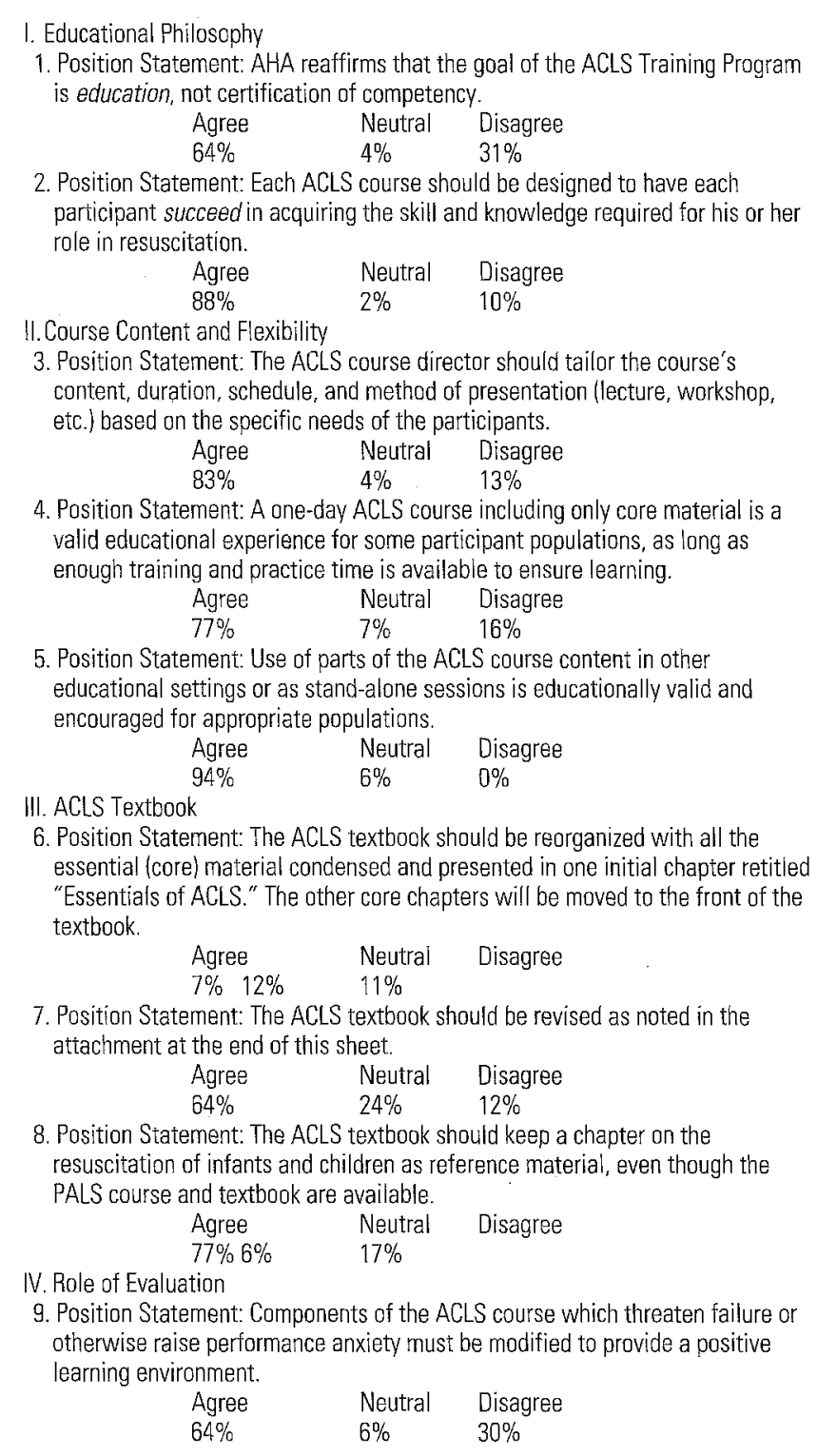




\section{EDUCATION IN ACLS}

Billi et al

10. Position Statement: The role of evaluation in ACLS courses should be to enhance the educational experience by providing a guide for instructors and individual participants to indicate problem areas which need further work.

$$
\begin{array}{lll}
\text { Agree } & \text { Neutral } & \text { Disagree } \\
78 \% & 7 \% & 15 \%
\end{array}
$$

11. Position Statement: Throughout the course, participants who have problems should receive remediation. The goal is to improve that participant's skills and knowledge as much as possible within the course constraints.

$$
\begin{array}{lll}
\text { Agree } & \text { Neutral } & \text { Disagree } \\
91 \% & 3 \% & 6 \%
\end{array}
$$

V.The Implications of Course Attendance

12. Position Statement: A full ACLS course should contain teaching stations covering airway intubation, arrhythmia recognition and therapy, electrical therapy, and megacode. A full ACLS course should also contain evaluation stations covering BLS, airway intubation, arrhythmia recognition and therapy, megacode, and a written examination. The terms pass, fail, satisfactory, and unsatisfactory should be eliminated from the "evaluation forms" (formerly "testing forms").

$$
\begin{array}{lll}
\text { Agree } & \text { Neutral } & \text { Disagree } \\
35 \% & 8 \% & 57 \%
\end{array}
$$

13. Position Statement: Only courses which include at least the core material and the ACLS teaching and evaluation stations mentioned in position statement 12 should be called "ACLS courses" for issue of course participation documentation.

$\begin{array}{lll}\text { Agree } & \text { Neutral } & \text { Disagree } \\ 96 \% & 2 \% & 2 \%\end{array}$

14. Position Statement: Documentation of ACLS course participation should be awarded to al/ participants when the following conditions are met

a. The course covers the core material;

b. The course includes evaluation of the participants, both in knowledge and skills, on core material; and

c. The individual participates throughout the course, including all teaching and evaluation activities of the course.

$$
\begin{array}{lll}
\text { Agree } & \text { Neutral } & \text { Disagree } \\
60 \% & 6 \% & 34 \%
\end{array}
$$

15. Position Statement: Documentation of ACLS course participation should be given to participants who meet the criteria in position statement 14 , even if evaluation stations show they need improvement in one or more areas of skill and knowledge.

$\begin{array}{lll}\text { Agree } & \text { Neutral } & \text { Disagree } \\ 36 \% & 4 \% & 61 \%\end{array}$

16. Position Statement: Documentation of ACLS course participation should be a letter rather than a card to lessen misunderstandings about the meaning of course participation.

$$
\begin{array}{lll}
\text { Agree } & \text { Neutral } & \text { Disagree } \\
29 \% & 22 \% & 48 \%
\end{array}
$$

17. Position Statement: The recommendation to retrain in ACLS every two vears should be deleted. Providers should retrain as needed, based on their role in resuscitation and how often they use their skills at work. Frequent refresher sessions are encouraged.

$$
\begin{array}{lll}
\text { Agree } & \text { Neutral } & \text { Disagree } \\
40 \% & 3 \% & 57 \%
\end{array}
$$

18. Position Statement: The program must encaurage instructors to strive to achieve the highest level of performance from each participant. The elimination of the terms pass and fail should not change the expectation of excellent performance.

$$
\text { Agree Neutral Disagree }
$$

$$
61 \% \quad 5 \% \quad 34 \%
$$

19. Position Statement: The evaluation forms should offer three possible evaluation ratings: good, fair, or needs improvement.

$$
\begin{array}{lll}
\text { Agree } & \text { Neutral } & \text { Disagree } \\
4.1 \% & 15 \% & 43 \%
\end{array}
$$

20. Position Statement: Course directors should give participants written evaluation results (eg, station grading sheets, written examination results) that may be shown to other institutions to substantiate their skill levels.

$$
\begin{array}{lll}
\text { Agree } & \text { Neutral } & \text { Disagree } \\
48 \% & 9 \% & 44 \%
\end{array}
$$

*Agree $=$ Strongly Agree and Agree

Disagree $=$ Strongly Disagree and Disagree.

The sum of percent responses on an item may not equal 100 due to rounding.

\section{Address for reprints:}

John E Billi, MD

University of Michigan Medical School

1301 Catherine Street

M7321 Medical Science Building I

Ann Arbor, Michigan 48109-0624 